\title{
PERBEDAAN KEKUATAN IKATAN KIMIA ANTARA BAHAN BONDING HEMA DENGAN PELARUT ASETON DENGAN BAHAN BONDING HEMA DENGAN PELARUT ETANOL PADA KOLAGEN
}

\author{
Adioro Soetojo $^{1}{ }^{1}$ Ivan Salomo Sumarto ${ }^{2}$, Moch. Mudjiono $^{1}$, Cecilia Lunardhi ${ }^{1}$ \\ ${ }^{1}$ Staf Pengajar Departemen Konservasi Gigi \\ Fakultas Kedokteran Gigi - Universitas Airlangga Surabaya - Indonesia \\ ${ }^{2}$ Mahasiswa Program Pendidikan Dokter Gigi Spesialis Konservasi Gigi
}

\begin{abstract}
ABSTRAK
Latar belakang: Resin komposit berikatan dengan struktur gigi melalui bahan adesif, yang dikenal dengan sebutan bahan bonding. Bahan bonding biasanya mengandung monomer fungsional yang spesifik pada umumnya adalah ester yang berasal dari reaksi alkohol bivalen dengan asam metakrilat dan phosphor atau derivate asam karboksilat.dalam studi terbaru terdapat ikatan bahan bonding secara kimia. Tujuan: Untuk menganalisis perbedaan kekuatan ikatan kimia antara bahan resin bonding berbahan dasar HEMA berpelarut etanol dan HEMA berpelarut aseton dengan kolagen dentin. Metode: Terdapat 3 kelompok pada penelitian ini. Kelompok pertama HEMA dan kolagen dicampur dengan $\mathrm{KBr}$, kelompok ini sebagai kontrol positif. Kelompok kedua HEMA, etanol, dan kolagen dicampur KBr. Kelompok ketiga HEMA, aseton, dan kolagen dicampur $K B r$. Ketiga kelompok kemudian dijadikan pellet bening dan dianalisa dengan FTIR, untuk kemudian dihitung nilai puncak pita serapan karbonil dari masing-masing kelompok penelitian. Data dianalisa menggunakan Kruskall Wallis dan Tukey HSD test ( $p$ <0.05). Hasil: Nilai Peak (P) pita serapan karbonil kelompok I: 71.36, kelompok II : 46.76, kelompok III : 27.2. Semakin kecil nilai Peak $(P)$ pita serapan karbonil maka diamsusikan semakin besar kekuatan ikatan secara kimia. Kesimpulan: Kekuatan ikatan kimia pada bahan bonding HEMA berpelarut aseton lebih besar dibandingkan dengan berpelarut etanol pada kolagen dentin.
\end{abstract}

Keywords: kolagen dentin, HEMA, aseton, etanol, FTIR, kekuatan ikatan kimia.

Korespondensi : Adioro Soetojo, Staf Pengajar Departemen Konservasi Gigi, Fakultas Kedokteran Gigi, Universitas Airlangga, Jl. Mayjen Prof. Dr. Moestopo 47 Surabaya, email : adioros-s@fkg.unair.ac.id

\section{PENDAHULUAN}

Dentin bersifat heterogen dan terdiri atas bahan anorganik (hidroksiapatit) $50 \%$ volume, bahan organik (khususnya kolagen tipe I) $30 \%$ volume dan cairan $20 \%$ volume. Resin komposit berikatan dengan struktur gigi melalui bahan adesif, yang dikenal dengan sebutan bahan bonding. Bahan bonding sebagai bahan untuk menggabungkan restorasi komposit dengan jaringan gigi, baik di enamel atau pada bagian dentin gigi. Umumnya bahan ini merupakan derivat dari resin metakrilat serta mudah untuk berpolimerisasi. Polimerisasi resin dentin bonding diperoleh dengan menggunakan sinar tampak (visible

light) yang berasal dari alat light curing unit. Resin ini dapat berpolimerisasi dengan sinar tampak oleh karena mengandung foto-inisiator yakni

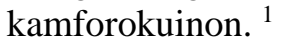

Bahan bonding biasanya mengandung monomer fungsional yang spesifik yang pada umumnya adalah ester yang berasal dari reaksi alkohol bivalent dengan asam metakrilat dan phosphor atau derivat asam karboksilat. ${ }^{2}$

Diantara banyaknya monomer fungsional yang tersedia sebagai bahan adesif, HEMA merupakan salah satu yang dipakai menjadi bahan dasar dari bahan adesif. Studi tentang dentin bonding berpendapat bahwa monomer 
fungsional spesifik dapat berinteraksi secara kimia dengan jaringan gigi. Keuntungan potensial yang didapatkan dari adanya interaksi kimia pada bahan dentin bonding menunjukkan adanya kontribusi pada sistem kerja dari bahan bonding yaitu memperlama ikatan adesif bonding. ${ }^{3}$

Faktor biologik dan kimia, keduanya merupakan hal yang relevan dalam memberikan perlekatan yang optimal pada struktur gigi, terutama pada daerah dentin. Berdasarkan prinsip dari formasi hybrid layer, demineralisasi dentin diikuti oleh infiltrasi resin yang adekuat dan juga polimerisasi yang merupakan kunci untuk medapatkan perlekatan yang kuat dan tahan lama. Pelarut ditambahkan ke dalam monomer untuk membantu monomer lebih berinfiltrasi ke dalam kolagen. Bahan pelarut yang biasa terdapat pada bahan bonding adalah aseton dan etanol., ${ }^{4,5,6}$

Pada pelarut organik seperti pada etanol dan aseton memiliki kemampuan menguap lebih tinggi yang dikarenakan oleh karena adanya tekanan yang berlebih. Penguapan yang terjadi pada dentin bonding akan menyebabkan viskositas dentin bonding akan meningkat sehingga lebih sulit untuk berilfiltrasi ke dalam dentin akan menyebabkan kekuatan perlekatan dentin bonding berkurang. ${ }^{4}$

Deteksi terdapatnya ikatan kimia antara bahan adhesif dengan kolagen tampak sebagai topik yang kontroversial di dalam beberapa literatur, oleh karena itu beberapa teknik digunakan untuk mengetahui adanya ikatan kimia pada bahan adhesive seperti menggunakan XPS (X-ray Photoelectron Spectroscopy), micromechanical test, dan khususnya alat yang bekerja dengan sistem spektrum infrared, FTIR (Fourier Transform InfraRed) spectroscopy memiliki spesial karakteristik dalam penelitian untuk mendeteksi penetrasi dan interaksi dari sebuah bahan adhesif ke dalam jaringan biologik. ${ }^{7}$

Perlekatan pada dentin tetap menjadi tantangan tersendiri sampai saat ini, diperlukan penelitian lebih lanjut tentang kekuatan perlekatan pada bahan adesif bonding, salah satunya dengan menggunakan uji kekuatan perlekatan kimia pada bahan adesif bonding terhadap kolagen.

\section{BAHAN DAN METODE}

Jenis penelitian ini adalah penelitian eksperimental laboratoris dengan rancangan penelitian Post Test Only Control Group Design. Sampel penelitian yang dipakai pada penelitian ini adalah kolagen tipe I (bovine). Penentuan jumlah sampel yang digunakan pada penelitian ini menggunakan rumus Lemeshow, didapatkan jumlah total sampel sebanyak 27. Sampel dibagi menjadi 3 kelompok, kelompok 1: HEMA diberi perlakuan dengan kolagen, kelompok 2: HEMA diberi perlakuan etanol dan kolagen, kelompok 3: HEMA diberi perlakuan aseton dan kolagen.

Pembuatan sampel pada penelitian ini adalah pada kelompok pertama, kolagen ditimbang seberat $2 \mathrm{mg}$, dan HEMA sebanyak $10 \quad \mu l \quad(10,7 \quad m g)$ kemudian diberi $\mathrm{KBr}$ hingga mencapai berat $313,7 \mathrm{mg}$. Pada kelompok kedua etanol diukur sebanyak $10 \mu$ l, kemudian dicampur dengan HEMA sebanyak $10 \mu \mathrm{l}$ $(10,7 \mathrm{mg})$ dan kolagen $2 \mathrm{mg}$, setelah tercampur kemudian ditambahkan $\mathrm{KBr}$ hingga mencapai berat $313,7 \mathrm{mg}$. Pada kelompok penelitian ketiga aseton diukur sebanyak $10 \mu \mathrm{l}$, kemudian dicampur dengan HEMA sebanyak $10 \mu 1$ $(10,7 \mathrm{mg})$ dan kolagen $2 \mathrm{mg}$, setelah tercampur kemudian ditambahkan $\mathrm{KBr}$ hingga mencapai berat $313,7 \mathrm{mg}$ (Gambar 1). Masing-masing dari ketiga kelompok penelitian tersebut dicampur hingga halus, kemudian dari masingmasing kelompok diambil $50 \mathrm{mg}$ untuk kemudian dimasukkan ke dalam $\mathrm{KBr}$ die, setelah itu $\mathrm{KBr}$ die dimasukkan ke dalam alat vacuum press, dengan tekanan 10 ton sehingga menghasilkan pellets bening (Gambar 2). Kemudian pellets bening dari masing-masing kelompok diobservasi menggunakan 
FTIR spectroscopy. Dari hasil observasi menggunakan FTIR spectroscopy, dihitung nilai Peak (P) pita serapan gugus karbonil $(\mathrm{C}=\mathrm{O})$ dengan menggunakan rumus $\mathrm{P}=\mathrm{BC} / \mathrm{AB} \times 100$.

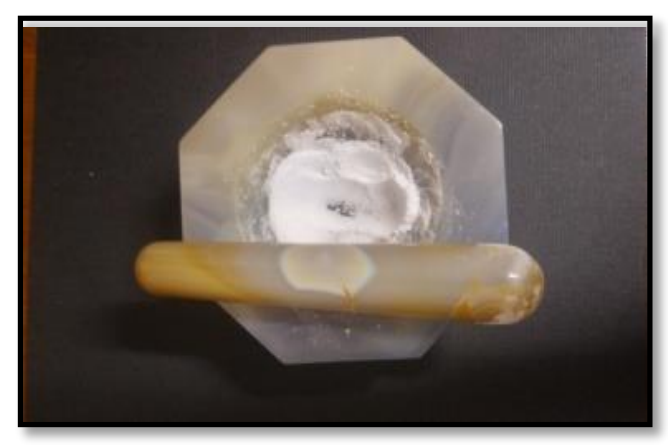

Gambar 1.Bahan campuran HEMA

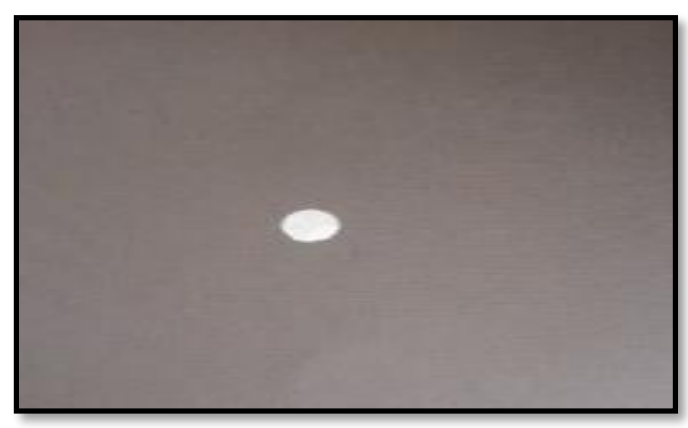

Gambar 2. Pellets bening

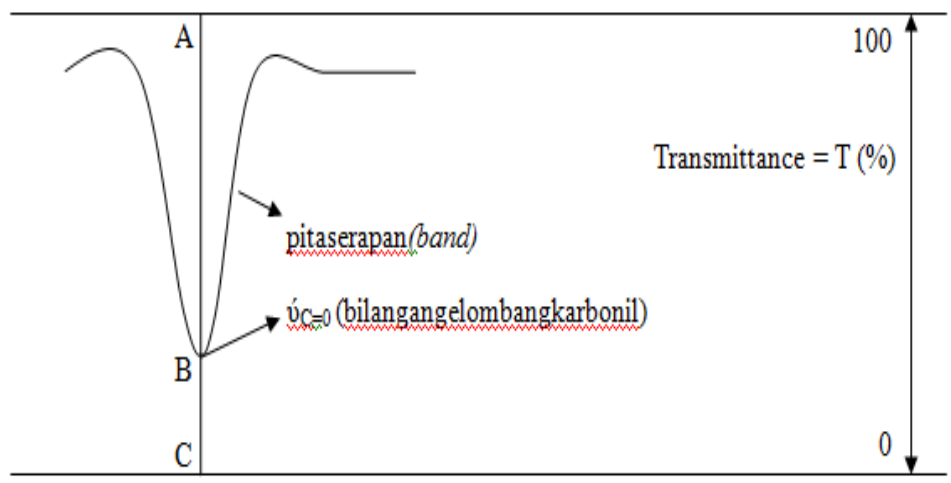

Gambar 3. Perhitungan Peak (P) pita serapan karbonil.

$\mathrm{P}=\mathrm{BC} / \mathrm{AB} \times 100$ 


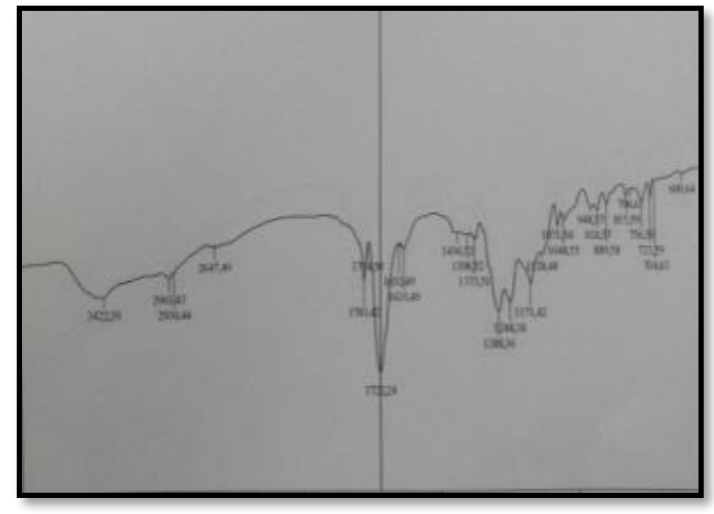

Gambar 4. Gambaran hasil observasi FTIR Spectroscopy

\section{HASIL}

Sebelum dilakukan uji beda kekuatan ikatan kimia antar kelompok, terlebih dahulu masing-masing kelompok diuji distribusi datanya terlebih dahulu dengan uji statistik Kolmogorov-Smirnov untuk mengetahui berdistribusi normal atau tidak dan homogenitas variansnya dengan uji Tabel 5.1 Nilai Rerata dan Standar Deviasi Kekuatan Ikatan Kimia antara Bahan Bonding HEMA

Berpelarut Etanol dengan Berpelarut Aseton pada Kolagen dentin

Pita Serapan

\begin{tabular}{|c|c|c|c|c|}
\hline & $\mathrm{N}$ & Mean & Std. Deviation & Std. Error \\
\hline HEMA+Kolagen & 9 & 71.3556 & 10.67346 & 3.55782 \\
\hline HEMA+Kolagen+Ethanol & 9 & 46.7556 & 5.97936 & 1.99312 \\
\hline HEMA+Kolagen+Aseton & 9 & 27.2000 & 3.67865 & 1.22622 \\
\hline Total & 27 & 48.4370 & 19.72654 & 3.79637 \\
\hline
\end{tabular}


Antar kelompok penelitian dilakukan uji Tukey HSD untuk mengetahui perbedaan antar kelompok.

Uji Tukey HSD dapat dilakukan karena jumlah antar sampel tiap kelompok sama

Tabel 5.2 Perbedaan Kekuatan Ikatan Kimia antara Bahan Bonding HEMA Berpelarut Etanol dengan Berpelarut Aseton pada Kolagen Tipe I

\begin{tabular}{|c|c|c|c|}
\hline Kelompok & $\begin{array}{c}\text { HEMA + } \\
\text { kolagen } \\
(\text { Kontrol +) }\end{array}$ & $\begin{array}{c}\text { HEMA + } \\
\text { kolagen + } \\
\text { etanol }\end{array}$ & $\begin{array}{c}\text { HEMA + } \\
\text { kolagen + } \\
\text { aseton }\end{array}$ \\
\hline $\begin{array}{c}\text { HEMA + } \\
\text { kolagen } \\
\text { (Kontrol +) }\end{array}$ & $0,000^{*}$ & $0,000^{*}$ \\
\hline $\begin{array}{c}\text { HEMA + } \\
\text { kolagen }+ \\
\text { etanol }\end{array}$ & $0,000^{*}$ & $0,000^{*}$ & $0,000^{*}$ \\
\hline $\begin{array}{c}\text { HEMA + } \\
\text { kolagen }+ \\
\text { aseton }\end{array}$ & $0,000^{*}$ & 0, & \\
\hline
\end{tabular}

${ }^{*} \mathrm{p}<0,05=$ terdapat perbedaan yang bermakna

Uji beda pada tabel 5.2 didapatkan bahwa ada perbedaan bermakna antara kelompok bahan bonding HEMA berpelarut aseton dengan kelompok HEMA dengan kolagen serta kelompok HEMA, etanol, dan kolagen yakni nilai $\mathrm{p}=0,000 \quad(\mathrm{p}<0,05)$. Nilai Peak $(\mathrm{P})$ serapan pita karbonil HEMA, aseton dan kolagen paling rendah, hal tersebut menunjukkan bahwa semakin rendah nilai Peak (P) maka semakin banyak molekul dari bahan bonding yang berikatan dengan kolagen, semakin banyak yang berikatan semakin kuat ikatan yang terbentuk secara kimia.

\section{PEMBAHASAN}

Studi tentang dentin bonding berpendapat bahwa monomer fungsional spesifik dapat berinteraksi secara kimia dengan jaringan gigi. Keuntungan yang didapatkan dari adanya interaksi kimia pada bahan dentin bonding menunjukkan adanya kontribusi pada sistem kerja dari bahan bonding yaitu memperlama ikatan adhesive bonding. ${ }^{8}$

Pelarut memiliki peran yang penting pada proses penetrasi dentin bonding pada kolagen dentin. Pelarut memiliki sifat fisik dan kimia yang membantu mempengaruhi dentin bonding untuk berpenetrasi ke dalam kolagen dentin, seperti viskositas, tegangan permukaan, parameter kelarutan dan H-bonding capacity, sehingga dengan penambahan pelarut pada bahan dentin bonding dapat meningkatkan ikatan kimia antara 
gugus fungsi pada monomer dan juga gugus fungsi pada kolagen dentin. Pelarut yang paling sering digunakan adalah etanol dan aseton dikarenakan memiliki sifat fisik dan kimia yang paling baik diantara pelarut yang lain. $^{4}$

Ikatan kimia yang terjadi antara HEMA dengan kolagen merupakan ikatan kovalen atau ikatan primer antar atom. Pada reaksi kimia akan terjadi pembentukan ikatan kovalen antara atom nitrogen dari kolagen dengan atom karbon pada aldehid resin. ${ }^{1}$

Penggunaan FTIR (fourier

Transform Infrared Photoacoustic Spectroscopy) pada bahan adhesif HEMA didapatkan bahwa kekuatan kimia pada dentin bonding sangat tergantung pada komposisi bahan adhesif yang memberi perbedaan pada reaksi transesterifikasi yang tergantung pada molekul adhesif dan grup kolagen hidroksil, interaksi kimia dari bahan adesif pada bagian dentin membentuk kompleks kalsium atau fosfat ester dan juga perlekatan ion antara gugus karboksilat dari bahan adhesif dan kalsium hidroksiapatit pada dentin, semakin banyak bahan penyusunnya kekuatan kimia antara matriks dentin anorganik semakin meningkat. ${ }^{8}$

Perlekatan kimia antara resin HEMA dengan kolagen dentin juga diteliti oleh Hiraishi et al., $2013^{9}$ yang melakukan penelitian dengan Saturation Transfer Difference NMR. Dinyatakan bahwa kekuatan ikatan kimia tersebut ditentukan oleh adanya kemampuan gugus fungsi dari monomer untuk mengikat molekul dari kolagen. Adanya interaksi hidrofobik antara gugus fungsi hidrofobik dari HEMA dengan permukaan kolagen yang hidrofobik.

Penggunaan pelarut etanol dan aseton juga memberikan pengaruh pada kekuatan geser dari sebuah monomer, pada penelitian yang dilakukan oleh
Koumpia et al., $2014^{10}$ disebutkan bahwa monomer yang menggunakan pelarut memiliki kekuatan geser lebih tinggi dibandingkan dengan monomer yang tidak menggunakan pelarut, hal ini disebabkan oleh karena kedua pelarut tersebut memiliki daya penguapan yang besar, sehingga bisa membantu penguapan kadar air dari permukaan dentin, dan membantu penetrasi dari monomer untuk masuk ke dalam fibril kolagen.

Dalam penelitian ini, untuk melihat signifikansi perbedaan antar kelompok perlakuan digunakan uji Kruskal wallis dan dilanjutkan uji Tukey HSD pada kelompok penelitian. Dari hasil analisa data nilai pita serapan karbonil terlihat bahwa terdapat berbedaan signifikan antara setiap perlakuan. Nilai serapan pita karbonil HEMA + Kolagen,+ Aseton lebih baik dibandingkan HEMA + Kolagen + Etanol. Semakin kecil nilai serapan pita karbonil, maka semakin banyak karbonil yang terserap, sehingga perlakuan terhadap nilai serapan pita karbonil yang paling baik adalah HEMA + Kolagen + Aseton, sedangkan perlakuan yang paling buruk adalah HEMA + Kolagen. Hal ini disebabkan oleh karena pada etanol memiliki H-bonding capacity yang besar sehingga apabila bahan dentin bonding diaplikasikan pada fibril kolagen yang kolaps akibat pengeringan yang berlebihan, etanol mampu mengembalikan kondisi fibril kolagen menjadi seperti semula dan membantu bahan dentin untuk berpenetrasi ke dalam fibril kolagen selain hal itu juga etanol mampu mengontrol jarak lebar dari rongga interfibriler selama proses penguapan sehingga tetap terjadi difusi yang baik antar monomer. ${ }^{4}$

Gugus aromatik dari HEMA bersifat hidrofobik dan akan menetralkan keasaman dan hidrofilisitas dari gugus karboksilat. Oleh karena itu pelarut yang paling optimal digunakan oleh bahan dentin bonding HEMA adalah aseton. Pada pelarut etanol kurang optimal apabila 
digunakan sebagai perlarut pada gugus asam karboksilat seperti salah satunya adalah HEMA dikarenakan terjadi reaksi esterifikasi dari gugus karboksilat dengan gugus hidroksil dari etanol, khususnya pada kondisi asam sehingga mengakibatkan inaktivasi dari gugus karboksilat untuk proses demineralisasi dan kemampuan adhesi. ${ }^{11}$

Pelarut aseton memiliki momen dipole yang tinggi dikombinasikan dengan konstanta dielektrik yang rendah yang memungkinkan untuk melarutkan senyawa polar dan apolar, oleh karena alasan tersebut aseton merupakan pilihan pelarut yang tepat bagi bahan denting bonding yang mengandung sifat hidrofilik dan hidrofobik. Aseton memiliki formasi ikatan hidrogen yang kebih rendah dengan keton $(\mathrm{C}=\mathrm{O})$ dibandingkan dengan alkohol (-OH), meskipun demikian aseton memiliki kemampuan ynag baik dalam hal water-removing capacity atau biasa disebut sebagai water chaser sehingga apabila aseton melarutkan HEMA akan terjadi penguapan yang tinggi, sisa air berkurang dan memudahkan monomer untuk berpentrasi ke dalam dentin. ${ }^{11}$

Pada pelarut aseton memiliki $H$ bonding capacity yang rendah, oleh karena itu maka pelarut aseton tidak dapat digunakan pada teknik $d r y$ bonding, karena tidak akan mampu mengembalikan lagi fibril kolagen setelah kolaps akibat demineralisasi. Aseton hanya dapat digunakan pada daerah yang lembab. Hal ini juga ditunjang dengan penelitian oleh Soetojo, 2006 ${ }^{3}$, bahwa kelembapan optimal untuk mendapatkan perlekatan yang bagus antara bahan dentin bonding dengan fibril kolagen sebesar $70 \%$ dikarenakan pada kelembapan $70 \%$ kondisi air sekitar fibril sangat optimal untuk terjadi inteaksi kimia monomer dentin bonding dengan fibril kolagen.

\section{KESIMPULAN}

Dari penelitian ini dapat diimpulkan bahwa kekuatan ikatan kimia antara bahan bonding HEMA berpelarut aseton lebih besar dibandingkan dengan berpelarut etanol pada kolagen dentin.

\section{DAFTAR PUSTAKA}

1. Anusavice, KJ.. Philip's Science of Dental Materials, $11^{\text {th }}$ Ed. WB. Philadelphia-London-Toronto

Saunders Co., 2013 : 21-395.

2. Nagakane, K., Yoshida, Y., Hirata, I., Fukuda, R., Nakayama, Y., Shirai, K., Ogawa, T., Suzuki, K., VanMeerbeek, B., dan Okazaki, M.. Analysis of Chemical Interaction of 4-MET with Hydroxyapatite Using XPS. Dental Materials Journal. 2006; 25 (4) : 645649.

3. Soetojo, A. Kekuatan Perlekatan Antara Bahan Bonding (HEMA) Dengan Kolagen Dentin Pada Berbagai Kelembapan. Disertasi. 2006. Program Pasca Sarjana Universitas Airlangga. Surabaya.

4. Ekambaran, M., Matinlinna, J. P., dan Yiu, C. 2014. An Overview of Solvents in Resin-Dentin Bonding. International Journal of Adhesion and Adhesives57 : 22-23

5. Lopes, G. C., Cardoso, P. C., Vieira, L. C. C., Baratieri, L. N., Rampinelli, K., dan Costa, G. Shear Bond Strength of Acetone-Based One-Bottle Adhesive Systems. Braz Dent J. 2006; 17(1) : 3943

6. Cardoso, P. C., Lopes, G. C., Vieira, L. C. C.,dan Baratieri, L. N. Effect of Solvent Type on Microtensile Bond Strength of a Total-etch One-Bootle Adhesives System to Moist or Dry Dentin. Operative Dentistry. 2005; 30(3) : 376-381.

7. Hargreaves, K. M., dan Berman, L. H. Cohen's Pathways of the Pulp, $11^{\text {th }}$ Edition. Mosby Inc, St Louis-LondonPhiladelphia, 2015; p : 411-454.

8. Ubaldini, A. L. M., Baesso, M. L., Sehn, E., Sato, F., Benetti, A. R., dan Pascotto, R. C. Fourier Transform 
Infrared Photoacoustic Spectroscopy Study of Physicochemical Interaction Between Human Dentin and Etch Rinse Adhesives in a Simulated Moist Bond Technique. Journal of Biomedical Optics, 2012; 17( 2) : 1-4.

9. Hiraishi, N., Tochio, N., Kigawa, T., Otsuki, M., dan Tagami, J. MonomerCollagen Interactions Studied by Saturation Transfer Difference NMR. J Dent Res. 2013; 92 (3) : p : 284-288.
10. Koumpia, E. K., Kouros, K., Koumpia, E., dan Antoniades, M. H. Shear Bond Strength of a " solventfree" Adhesives Versus Contemporary Adhesives Systems. Braz J Oral Sci. 2014; 13(1) : 64-69.

11. Landuyt, V. K. L., Snauwaert, J., De Munck, J., Peumans, M., Yoshida, Y., Poitevin. Systematic review of the chemical composition of contemporary dental adhesives. Biomaterials. 2007; 28 (3) : 757-85. 